\title{
Case Report: Mosaicism of a novel nonsense variant in the neurofibromin gene underlies a mosaic generalized NF1 phenotype [version 1; peer review: 2 approved]
}

\author{
Hui Li Kwong1', Yong-Kwang Tay'1, Ene-Choo Tan (iD)2,3 \\ ${ }^{1}$ Changi General Hospital, Singapore, Singapore, Singapore \\ ${ }^{2}$ KK Women's and Children's Hospital, Singapore, Singapore \\ ${ }^{3}$ Paediatrics Academic Clinical Programme, SingHealth Duke-NUS Medical School, Singapore, Singapore
}

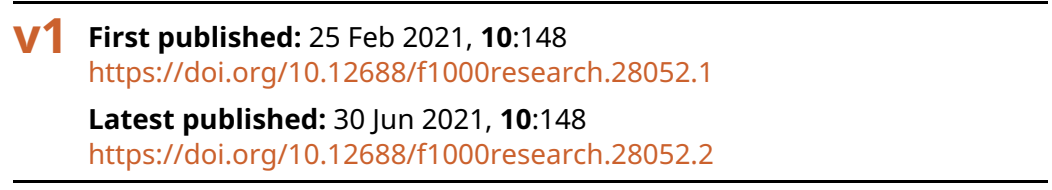

\section{Abstract}

Neurofibromatosis 1 (NF1) is a neurocutaneous syndrome characterized by multiple café-au-lait macules, cutaneous neurofibromas or plexiform neurofibromas, iris Lisch nodules, axillary and inguinal freckling. Mosaicism in NF1 can either present as a generalized disease, or in a localized (segmental) manner. Mosaic generalized NF1 may have presentations that are similar to generalized NF1 or have a milder phenotype and hence may be under-recognised in clinical practice. We report a nonsense mutation in the NF1 gene in a 55-year old Chinese male with the mosaic generalized phenotype. He reported noticing increasing numbers of skin-colored papules over his face, neck, back and abdomen when he was about 40 years old. From both next-generation and Sanger sequencing data, the variant appeared to be mosaic and present at about $24 \%$. It is in exon 39 and has not been reported in any database or published literature.

\section{Keywords}

mosaicism, mutation, neurofibromatosis 1, sequencing

\section{Open Peer Review}

Approval Status

1

2

\section{version 2}

(revision)

30 Jun 2021

\section{version 1}

$25 \mathrm{Feb} 2021$

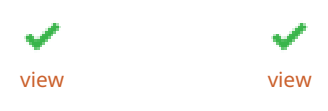

1. Richard J. Antaya (ID), Yale University School of Medicine, New Haven, USA

2. Joshua Tay, National University of Singapore, Singapore, Singapore

Any reports and responses or comments on the article can be found at the end of the article.

This article is included in the Cell \& Molecular

Biology gateway. 
Corresponding author: Ene-Choo Tan (tan.ene.choo@kkh.com.sg)

Author roles: Kwong HL: Investigation, Writing - Original Draft Preparation; Tay YK: Conceptualization, Investigation, Supervision, Writing - Review \& Editing; Tan EC: Conceptualization, Data Curation, Formal Analysis, Funding Acquisition, Investigation, Methodology, Project Administration, Resources, Validation, Writing - Review \& Editing

Competing interests: No competing interests were disclosed.

Grant information: This work was supported by NMRC/CG/006/2013 and NMRC/CG/M003/2017 from the Singapore Ministry of Health's National Medical Research Council.

The funders had no role in study design, data collection and analysis, decision to publish, or preparation of the manuscript.

Copyright: @ $2021 \mathrm{Kwong} \mathrm{HL}$ et al. This is an open access article distributed under the terms of the Creative Commons Attribution License, which permits unrestricted use, distribution, and reproduction in any medium, provided the original work is properly cited.

How to cite this article: Kwong HL, Tay YK and Tan EC. Case Report: Mosaicism of a novel nonsense variant in the neurofibromin gene underlies a mosaic generalized NF1 phenotype [version 1; peer review: 2 approved] F1000Research 2021, 10:148 https://doi.org/10.12688/f1000research.28052.1

First published: 25 Feb 2021, 10:148 https://doi.org/10.12688/f1000research.28052.1 


\section{Introduction}

Neurofibromatosis 1 (NF1, OMIM\#162200) is a neurocutaneous syndrome characterized by café-au-lait macules, cutaneous neurofibromas or plexiform neurofibromas, iris Lisch nodules, axillary and inguinal freckling ${ }^{1}$. Other features include optic nerve gliomas, central nervous system tumours, and long bone deformities. The autosomal dominant condition is caused by mutations or deletions involving the neurofibromin 1 gene (NF1, OMIM*613113) at chromosome 17q11.2, one of the largest human genes $(282 \mathrm{~kb})$ with 57 exons and three alternatively spliced transcripts ${ }^{2}$. Over 3600 clinically significant NF1 variants are documented in the Human Gene Mutation Database (HGMD). They are distributed over the whole gene from the first to the last exon.

The estimated incidence of germline NF1 is 1:2500-3000, with approximately half due to de novo mutations and the other half inherited from an affected parent. The disease is highly penetrant and although the offspring are at 50\% risk of inheriting a mutation, the manifestations are extremely variable even for family members who share the same mutation ${ }^{1}$. Non-germline or mosaic NF1 is very rare at 1:36,000-40,000, although it is probably under-reported as most cases are diagnosed clinically and molecular confirmation is not always performed ${ }^{3}$.

\section{Case report}

We report a patient with adult-onset NF1 presentations. The 55-year-old male engineer of Chinese ancestry presented in 2015 with increasing numbers of skin-colored papules over the past 13 years. He did not recall having these lesions earlier in life. Excision of one such representative lesion measuring $0.5 \mathrm{~mm} \times 0.5 \mathrm{~mm}$ from the right lateral neck was consistent with a neurofibroma. He was referred to dermatology and neurology departments on suspicion of neurofibromatosis.

Clinically the patient had more than 20 small, soft, fleshcoloured papules and small nodules (ranging between 4 and $10 \mathrm{~mm}$ ) on his face, neck, trunk and limbs. There was no axillary or inguinal freckling. He also had multiple scattered café-au-lait macules on his trunk. There were no lesions to suggest plexiform neurofibromas and no clinical evidence of long bone deformities. Slit-lamp examination revealed the presence of Lisch nodules in both irises. He had three older siblings, none of whom had similar skin lesions. Neither his parents nor members of his extended family had any features of neurofibromatosis. His two daughters (aged 17 and 21 years) were well with no features of neurofibromatosis. His other medical history was only significant for hyperlipidaemia for which he was on simvastatin (20 mg nightly) and cervical spondylosis which did not require intervention and he is no longer on active follow-up with the orthopaedics department.

Approval for sequencing analysis was obtained from the SingHealth Institutional Review Board (CIRB Ref 2014/207/F). Venous blood was collected from the patient after written informed consent and genetic counselling. Next-generation sequencing on genomic DNA was performed using a customised targeted panel (which covered all NF1 exons and NF1-related genes) with the Agilent Haloplex Target Enrichment System (Agilent Technologies, Santa Clara, USA) and the MiSeq System (Illumina, San Diego, USA). Output reads were processed using the MiSeq Reporter pipeline and variants were annotated with ANNOVAR (20190ct24) ${ }^{4}$. A heterozygous single nucleotide substitution in the NF1 gene that is predicted to result in premature termination: NM_000267.3: 5612T>A (p.L1871X) was identified. The number of reads for the variant was 28 out of 117 . The presence of the variant was confirmed in our laboratory by Sanger sequencing using BigDye Terminator v3.1 in a volume of $10 \mu \mathrm{l}$. Amplification conditions included initial denaturation at $96^{\circ} \mathrm{C}$ for $1 \mathrm{~min}$, followed by 25 cycles of $96^{\circ} \mathrm{C}$ for $10 \mathrm{sec}, 50^{\circ} \mathrm{C}$ for $5 \mathrm{sec}$; and $60^{\circ} \mathrm{C}$ for $4 \mathrm{~min}$. Following ethanol purification, the products were resuspended in $\mathrm{Hi}^{-\mathrm{Di}^{\mathrm{TM}}}$ formamide and loaded onto the ABI 3130 Genetic Analyzer (Applied Biosystems, Foster City, USA). The peak height of the variant was found to be approximately one-quarter to one-third that of the wild-type for both forward and reverse primers, confirming the mosaicism (Figure 1).

The variant identified has not been reported in any population databases and is not found in ClinVar or the Human Gene Mutation Database. However, a missense variant involving the same codon changing it to a phenylalanine residue has been reported in a patient with $\mathrm{NF} 1^{5}$. A search of the ClinVar database found several variants within 10 nucleotides identified from patients with NF1 or hereditary cancer-predisposing syndrome, indicating that this small region might be more prone to spontaneous mutations (Table 1).

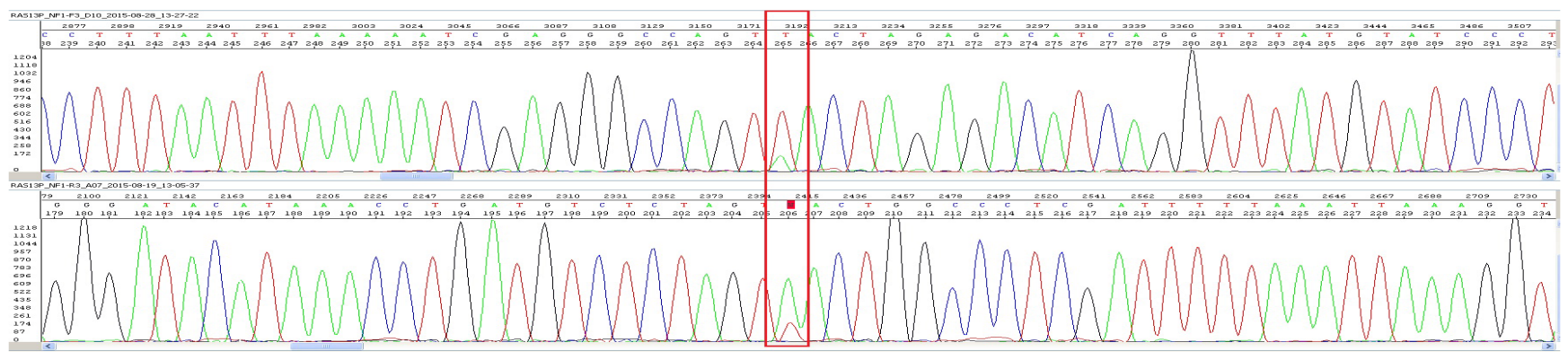

Figure 1. Chromatogram from Sanger sequencing for the c.5612T>A variant using forward primers (top) and reverse primers (bottom). Shown is the wildtype T allele with a small peak for the variant allele A (rectangular box). 
Table 1. ClinVar record of variants within 10 nucleotides of the identified c.5612T>A variant.

\begin{tabular}{|c|c|c|c|c|c|}
\hline Accession & Variant & $\begin{array}{l}\text { Protein } \\
\text { change }\end{array}$ & Transcript ID & Condition & Interpretation \\
\hline VCV000663647 & $5605 G>T$ & G1869C & NM_000267.3 & NF1 & Uncertain significance \\
\hline VCV000578661 & $5606 \mathrm{G}>\mathrm{T}$ & G1869V & NM_000267.3 & NF1 & Uncertain significance \\
\hline VCV000654611 & 5606_5627del & G1869fs & NM_000267.3 & NF1 & Pathogenic \\
\hline VCV000237577 & $5608 C>T$ & Q1870* & NM_000267.3 & NF1 & Pathogenic \\
\hline VCV000431662 & 5609dup & L1871fs & NM_000267.3 & NF1 & Pathogenic \\
\hline VCV000457758 & $5610 G>A$ & Q1870* & NM_000267.3 & NF1 & Likely benign \\
\hline VCV000825851 & $5673 G>T$ & Q1870H & NM_001042492.3 & HCPS & Uncertain significance \\
\hline VCV000547665 & $5613 A>C$ & L1871F & NM_000267.3 & NF1 & Uncertain significance \\
\hline VCV000547666 & 5613dup & L1872fs & NM_000267.3 & NF1 & Pathogenic \\
\hline VCV000229667 & $5613 A>G$ & L1871= & NM_000267.3 & HCPS & Likely benign \\
\hline VCV000957518 & 5672_5673ins & L1871fs & NM_001042492.3 & NF1 & Pathogenic \\
\hline VCV000653673 & $5617 \mathrm{G}>\mathrm{T}$ & E1873* & NM_000267.3 & NF1 & Pathogenic \\
\hline VCV000457759 & $5617 \mathrm{G}>\mathrm{C}$ & E1873Q & NM_000267.3 & NF1 & Uncertain significance \\
\hline
\end{tabular}

HCPS, Hereditary cancer-predisposing syndrome; NF1, Neurofibromatosis Type 1.

"Interpretation is based on submission in ClinVar.

\section{Discussion}

Mosaic NF1 was previously known as segmental NF1. It was initially defined as clinical features of NF1 limited to one or more segments of the body. The mosaicism which is caused by postzygotic mutation in the NF1 gene in somatic cells can present as a generalized disease or in a localized (segmental) manner ${ }^{6,7}$. Mosaic generalized patients may be clinically indistinguishable from generalized NF1 patients or have a milder phenotype $^{8}$. In contrast, the cutaneous manifestations of mosaic localized NF1 reflects the pattern of skin mosaicism and can vary from a narrow strip, one-quadrant, or half the body, unilaterally or bilaterally, in a symmetrical or asymmetrical fashion. Mosaic-localized NF1 patients may develop only pigmentary changes or neurofibromas, have a combination of pigmentary and neurofibromas, or have plexiform neurofibromas only ${ }^{7,9,10}$.

Like generalized NF1, mosaic NF1 presents with pigmentary features and plexiform neurofibroma arising in childhood, and dermal neurofibromas usually in adulthood. However, not all patients with mosaic NF1 with pigmentary changes develop neurofibromas. Patients may also develop learning difficulties, pseudoarthrosis and malignancy, despite having a milder phenotype ${ }^{3,10,11}$. Our patient is cognitively normal and had noticed the development of neurofibromas while in his late thirties. He also had Lisch nodules, which were not frequently observed regardless of the patient's age in other cohorts ${ }^{3,6,12}$. He is currently on annual follow-up for his cutaneous presentations.
Most cases of mosaic NF1 did not have molecular confirmation of the presence of an NF1 mutation, but genetic analysis was performed in a case series of eight patients with segmental NF1 from Canada. Sequencing of DNA from skin lesions revealed a pathogenic loss-of-function variant in the NF1 gene in all eight: six were single or multi-nucleotide variants, while the other two were microdeletions. Seven out of the eight patients had pigmentary changes (cafe-au-lait macules and axillary freckling) - three had non-localized lesions and one had lesions crossing the midline. The eighth patient had cafe-au-lait macules, a plexiform neurofibroma and sphenoid wing dysplasia but no freckling. Only one patient had Lisch nodules ${ }^{12}$.

The risk of passing on full-blown or localized disease to future generations is $50 \%$ for those with germline mutations. Although gonadal or gonosomal mosaicism is rare; individuals with mosaic NF1 mutation may transmit the mutation to their offspring in such cases $^{3,13}$. Thus, patients with mosaic NF1 should be counselled regarding the possibility of gonadal NF1 mosaicism and the risk of transmission to the next generation, especially when the mutation is also present in non-dermal tissues. Our patient had $24 \%$ mosaicism based on the number of reads from next-generation sequencing results of DNA from his peripheral blood. He was not evaluated for somatic or gonosomal mosaicism. His two daughters appear to have no features of NF1, although he is considering genetic testing for his children. 
In summary, we report a novel nonsense mutation in the NF1 gene, resulting in a mosaic generalized phenotype of NF1. Studies have sought to examine the genotype-phenotype correlation in mosaic localized NF1, although there is little in the literature regarding mosaic generalized NF1, which may be under-recognized given the clinical similarities with classic NF1. Future genotype-phenotype correlation studies in mosaic generalized NF1 would lead to better understanding of the disease development process and long-term outcomes. With better sequencing technology that can detect low-level mosaicism, molecular confirmation should be carried out to enable healthcare professionals to provide more accurate prognosis and genetic counselling.

\section{Data availability}

ClinVar accession number: SCV001450721.

\section{Consent}

Written informed consent for publication of the clinical details was obtained from the patient.
1. Friedman JM: Neurofibromatosis 1. In: GeneReviews ${ }^{\circledR}$ (eds. Adam, M.P. et al.) University of Washington, Seattle, Seattle (WA), 2019. PubMed Abstract

2. Hinman MN, Sharma A, Luo G, et al: Neurofibromatosis type 1 alternative splicing is a key regulator of Ras signaling in neurons. Mol Cell Biol. 2014; 34(12): 2188-97.

PubMed Abstract | Publisher Full Text | Free Full Text

3. García-Romero MT, Parkin P, Lara-Corrales I: Mosaic Neurofibromatosis Type 1: A Systematic Review. Pediatr Dermatol. 2016; 33(1): 9-17. PubMed Abstract | Publisher Full Text

4. Chang $X$, Wang K: wANNOVAR: annotating genetic variants for personal genomes via the web. J Med Genet. 2012; 49(7): 433-6. PubMed Abstract | Publisher Full Text | Free Full Text

5. Duat Rodríguez A, Moreno GAM, Santo-Domingo YM, et al.: [Phenotypic and genetic features in neurofibromatosis type $\mathbf{1}$ in children]. An Pediatr (Barc). 2015; 83(3): 173-82.

PubMed Abstract | Publisher Full Text

6. Ruggieri M, Huson SM: The clinical and diagnostic implications of mosaicism in the neurofibromatoses. Neurology. 2001; 56(11): 1433-43. PubMed Abstract | Publisher Full Text

7. Huson S, Hughes R: Chapter 41, The Neurofibromatoses. Textbook of Paediatric Dermatology. Oxford: Wiley-Blackwell, Oxford, 2006.
8. Jouhilahti EM, Peltonen S, Heape AM, et al.: The pathoetiology of neurofibromatosis 1. Am J Pathol. 2011; 178(5): 1932-9. PubMed Abstract | Publisher Full Text | Free Full Text

9. Moss C, Green $\mathrm{SH}$ : What is segmental neurofibromatosis? $\mathrm{Br}$ । Dermatol. 1994: 130(1): 106-10. PubMed Abstract | Publisher Full Text

10. Ruggieri M: Mosaic (segmental) neurofibromatosis type 1 (NF1) and type 2 (NF2): no longer neurofibromatosis type 5 (NF5). Am J Med Genet. 2001; 101(2): 178-80. PubMed Abstract | Publisher Full Text

11. Vázquez-Osorio I, Duat-Rodríguez A, García-Martínez FJ, et al: Cutaneous and Systemic Findings in Mosaic Neurofibromatosis Type 1. Pediatr Dermatol. 2017; 34(3): 271-276.

PubMed Abstract | Publisher Full Text

12. Marwaha A, Malach J, Shugar A, et al.: Genotype-phenotype data from a case series of patients with mosaic neurofibromatosis type 1. Br J Dermatol 2018; 179(5): 1216-1217.

PubMed Abstract | Publisher Full Text

13. Consoli C, Moss C, Green S, et al.: Gonosomal mosaicism for a nonsense mutation (R1947X) in the NF1 gene in segmental neurofibromatosis type 1. J Invest Dermatol. 2005; 125(3): 463-6. PubMed Abstract | Publisher Full Text 


\section{Open Peer Review}

\section{Current Peer Review Status:}

\section{Version 1}

Reviewer Report 18 June 2021

https://doi.org/10.5256/f1000research.31028.r83797

(C) 2021 Tay J. This is an open access peer review report distributed under the terms of the Creative Commons Attribution License, which permits unrestricted use, distribution, and reproduction in any medium, provided the original work is properly cited.

\section{Joshua Tay}

Department of Otolaryngology-Head and Neck Surgery, National University of Singapore, Singapore, Singapore

This is a well written article demonstrating a thorough genomic evaluation of the NF1 gene in an adult-onset NF1 patient. The NF1 mutation identified was present on both NGS (23.9\%) and Sanger sequencing (1/3 to $1 / 4)$ at similar variant allele frequencies, supporting the mosaicism.

Mosaic generalized NF1 is less commonly seen in the clinic compared to its well-known, germline NF1 counterpart. I agree with the authors that this could also be a result of an under-recognition of mosaic cases, given their clinical similarities. NGS diagnostics and recognizing the importance of variant allele frequencies, like those presented here, provides an opportunity to close this gap.

Is the background of the case's history and progression described in sufficient detail? Yes

Are enough details provided of any physical examination and diagnostic tests, treatment given and outcomes?

Yes

Is sufficient discussion included of the importance of the findings and their relevance to future understanding of disease processes, diagnosis or treatment?

Yes

Is the case presented with sufficient detail to be useful for other practitioners? Yes

Competing Interests: No competing interests were disclosed.

Reviewer Expertise: I am an Otolaryngology surgeon with a PhD in Cancer Biology, focusing on 
cancer genomics and molecular subtypes of disease.

I confirm that I have read this submission and believe that I have an appropriate level of expertise to confirm that it is of an acceptable scientific standard.

Reviewer Report 15 March 2021

https://doi.org/10.5256/f1000research.31028.r80275

(C) 2021 Antaya R. This is an open access peer review report distributed under the terms of the Creative Commons Attribution License, which permits unrestricted use, distribution, and reproduction in any medium, provided the original work is properly cited.

\section{Richard J. Antaya to}

Departments of Dermatology and Pediatrics, Yale University School of Medicine, New Haven, CT, USA

This is an enlightening and well written case report that brings to light a variant of a common genetic syndrome.

1. In the introduction the authors state that that non-germline or mosaic NF-1 is very rare, however they report that it is about 10 times less common than germline NF-1, which is actually relatively common. I would agree it is rare, but not very rare. The statement that many cases of generalized mosaic NF1 are likely undiagnosed is likely true and would further decrease the scarcity of this disorder.

2. In the description of the case, the authors state that the patient had café au lait macules (CALMs) on his trunk, but do not state the size, number, and especially the duration of these lesions. In germline NF-1 CALMs generally precede the development of neurofibromas by often a decade or more. I think this is important information to include for the readership.

3. I feel that only gonadal mosaicism should be used in this discussion since the term gonosomal is relating primarily to sex chromosomes, and ch17, the chromosome with the mutation of interest, is an autosome.

4. While not clear from the discussion, have any studies evaluated the percent mutated cells in somatic tissue, skin versus blood, in patients with either generalized or segmental mosaic NF1. Since patients with cutaneous "segmental" NF1 are known to harbor the mutation in other tissues and pass on the disease to offspring, do these individuals have a form or generalized mosaic NF1 or is it tissue/area specific? I understand if this info is not available.

Is the background of the case's history and progression described in sufficient detail? Partly

Are enough details provided of any physical examination and diagnostic tests, treatment given and outcomes?

Yes 
Is sufficient discussion included of the importance of the findings and their relevance to future understanding of disease processes, diagnosis or treatment?

Yes

Is the case presented with sufficient detail to be useful for other practitioners?

Yes

Competing Interests: No competing interests were disclosed.

Reviewer Expertise: I am an academic pediatric dermatologist with a cursory understanding of the details regarding the methodology of genetic mutation analysis but am very familiar with the cutaneous manifestations of NF1 and segmental NF1.

I confirm that I have read this submission and believe that I have an appropriate level of expertise to confirm that it is of an acceptable scientific standard.

Author Response 23 Jun 2021

\section{Ene Choo Tan}

We have deleted the word "very" from "very rare" in the Introduction. We also added more details about the patient, including his ethnicity and that his parents are not consanguineous, and the size and duration of his lesions. We also changed "gonosomal" to "gonadal" as suggested.

Competing Interests: None

The benefits of publishing with F1000Research:

- Your article is published within days, with no editorial bias

- You can publish traditional articles, null/negative results, case reports, data notes and more

- The peer review process is transparent and collaborative

- Your article is indexed in PubMed after passing peer review

- Dedicated customer support at every stage

For pre-submission enquiries, contact research@f1000.com 